\title{
Maternal Emotional Availability and Its Association with Maternal Psychopathology, Attachment Style Insecurity and Theory of Mind
}

\author{
Maria Licata ${ }^{a}$ Anna-Lena Zietlow ${ }^{c}$ Birgit Träuble ${ }^{d}$ Beate Sodian $^{b}$ \\ Corinna Reck ${ }^{b}$ \\ ${ }^{a}$ Department of Social Pediatrics, Technical University, and ${ }^{b}$ Department of Psychology, Ludwig-Maximilian \\ University, Munich, 'Institute of Psychology, University of Heidelberg, Heidelberg, and ${ }^{\mathrm{d}}$ Department of Psychology, \\ University of Cologne, Cologne, Germany
}

\section{Key Words}

Anxiety disorders · Postpartum depression $\cdot$ Mother-child interaction $\cdot$ Attachment $\cdot$ Theory of mind

\section{Abstract}

Background/Aims: High maternal emotional availability (EA) positively affects various domains of child development. However, the question of which factors promote or hinder maternal EA has not been investigated systematically. The present study investigated several maternal characteristics, namely maternal psychopathology, maternal attachment style insecurity, and theory of mind (ToM) as possible factors that influence maternal EA. Methods: The sample was comprised of 56 mothers and their preschoolaged children. Half of the mothers were diagnosed with postpartum depression and or anxiety disorders according to DSM-IV, and the other half were healthy controls. Results: The results showed that both low maternal attachment style insecurity and high ToM skills significantly predicted maternal EA sensitivity, independently from maternal postpartum and concurrent psychopathology and education. Moreover, maternal attachment style insecurity fully mediated the link

\section{KARGER}

E-Mail karger@karger.com www.karger.com/psp between maternal postpartum psychopathology and sensitivity. Conclusion: The findings suggest that maternal attachment style security can buffer negative effects of maternal psychopathology on maternal sensitivity in the motherchild interaction.

(c) 2016 S. Karger AG, Basel

\section{Introduction}

The construct of maternal emotional availability (EA) has been developed to measure the emotional quality of the mother-child interaction from infancy to late childhood [1]. Based on the attachment theoretical assumption that the quality of a child's experiences with his caregiver affects his development [2,3], maternal EA has been shown to be related to diverse domains of child development. In particular, maternal EA has been linked to child attachment security [4-6]. Moreover, longitudinal studies have shown that high EA predicts better emotion regulation [7], lower rates of psychopathological symptoms $[6,8]$, higher social competence [9], better language skills and general mental development [10], and better theory 
of mind (ToM) skills in children [11]. Thus, several empirical findings underline the huge significance of high maternal EA for healthy child development.

As maternal EA has been shown to have an impact on various areas of child development, it is important to identify factors that promote or hinder high EA. There is an indication that maternal depression, particularly in the postpartum period, negatively affects the interaction quality between a mother and her infant $[12,13]$ and, consequently, child development $[14,15]$. Easterbrooks et al. [16] found a negative effect of maternal postpartum depression on two dimensions of EA, namely maternal sensitivity and structuring, when children were 7 years old, even when controlling for concurrent maternal depression. Furthermore, our work group found a significant association between maternal psychopathology, child responsiveness as measured by the Emotional Availability Scales (EAS), and child internalizing behavior at preschool age in a study dealing with the same sample [17].

Besides maternal depression, anxiety disorders are also highly prevalent in the postpartum period, with a prevalence of up to $11 \%$ [18]. However, there is quite little research regarding the relation between postpartum maternal anxiety disorders and the mother-child interaction, and there are no studies regarding maternal EA. There is one study showing that lower levels of maternal posttraumatic stress symptoms were associated with higher maternal sensitivity, structuring, and nonhostility [19].

Moreover, mothers with reduced sensitivity often have an insecure attachment representation [20] which increases the risk for maternal depression and anxiety disorders [21]. Studies report a positive relation between maternal secure attachment representation assessed by the Adult Attachment Interview (AAI [22]) and sensitivity and structuring as assessed by the EAS $[23,24]$. Moreover, some studies also report links between maternal attachment style, usually measured via self-report questionnaires (e.g. the Relationship Scales Questionnaire, RSQ [25] or the Vulnerable Attachment Style Questionnaire, VASQ [26]), and the mother-child interaction quality. Whereas attachment representation refers to the adult's unconscious internal working model about relationships [22], attachment style refers to a predominantly conscious, systematic pattern of relational expectations, emotions, and behaviors that emerges from the internalization of specific attachment experiences through time [27]. Edelstein et al. [28] found that parents scoring high on self-reported attachment avoidance in couple re-

Maternal EA, Psychopathology,

Attachment and ToM lationships assessed by the RSQ [25] showed less overall EA when their child was distressed than parents scoring low on attachment avoidance.

So far, no study has investigated the link between maternal social-cognitive competencies and the motherchild interaction quality. However, theoretical accounts have pointed out the strong connection between social cognition and social interaction [29]. The capacity to ascribe mental states to oneself and others and to anticipate behavior is referred to as ToM [30] and is regarded as the core component of social cognition. A specific social-cognitive characteristic of a parent refers to the tendency to view the child as a psychological agent attributing mental states to the child, which is referred to as mind-mindedness [31]. Lok and McMahon [32] reported that maternal mind-mindedness was positively related to nonhostility as assessed by the EAS. There is a conceptual link between mind-mindedness and ToM, as both concepts focus on the correct interpretation of mental states. However, whereas mind-mindedness refers to the mother's correct mental state attributions with regard to the child [31], ToM refers to the correct attribution of mental states in general [30]. Thus, one might assume that a mother who is able to correctly ascribe mental states to other persons (ToM) should also be able to react appropriately to the child's emotional expressions, which constitutes an important aspect of EA.

In sum, there are several maternal characteristics that supposedly influence maternal EA. The aim of the study was to systematically investigate several maternal characteristics with regard to their impact on maternal EA at children's preschool age. Based on attachment theoretical accounts as well as previous empirical findings, we assumed that maternal psychopathology, attachment style, and ToM would be linked to maternal EA. More specifically, we supposed that the presence of maternal depression and/or anxiety disorders would have an impact on maternal EA, in particular on maternal sensitivity and structuring at preschool age [17]. As depression and anxiety disorders often negatively affect the mother-child interaction, expressed in lower maternal sensitivity, both are associated with maternal attachment. Therefore, we hypothesized that maternal attachment style insecurity would mediate the relationship between maternal postpartum depression and/or anxiety disorders and maternal EA at children's preschool age. Maternal education was included as a control variable because studies indicate a significant relation between maternal education/socioeconomic status and maternal EA [32]. 


\section{Methods}

\section{Procedure and Participants}

Data were collected from 2004 to 2011 in two middle-sized towns in Southern Germany. Participants took part in a longitudinal study dealing with the impact of maternal postpartum depression and anxiety disorders on the mother-infant interaction and child development $[17,33-35]$. Subjects were recruited in local maternity hospitals and at the mother-infant unit of the University Hospital Heidelberg. The screening procedure is described in detail elsewhere [36]. The German version of the Structured Clinical Interview for DSM-IV Axis-I Disorders (SCID-I [37]) was completed at two assessments: the first $\left(\mathrm{T}_{1}\right)$ within 9 months after delivery and the second $\left(\mathrm{T}_{2}\right) 3-6$ years later (mean $=4.6$ years). At $\mathrm{T}_{2}$, in addition to the SCID, maternal attachment style insecurity was assessed using the VASQ [38]. Moreover, maternal ToM was measured using a combination of the Strange Stories and the ToM stories $[39,40]$, and the mother-child interaction quality was assessed using the EAS [41]. The initial sample size $(n=66)$ was reduced to 56 due to incomplete follow-up questionnaires of the participants. The women were allocated to the corresponding group due to their postpartum mental health status assessed with the SCID-I at $\mathrm{T}_{1}$. All women in the clinical group fulfilled the criterion of the additional code 'postpartum' according to the DSM-IV with an onset within 4 weeks after delivery. Women with one or more of the following diagnoses at $\mathrm{T}_{1}$ were assigned to the clinical group $(n=27)$ : major depression, generalized anxiety disorder, agoraphobia, panic disorder, and social phobia. Of the 27 women who had been diagnosed with depression and/or anxiety disorders in the postpartum period, 15 were diagnosed with current SCID diagnoses (depression and/or anxiety disorders) at $\mathrm{T}_{2}$. The control group was comprised of 29 women without current, or a history of, psychiatric disorders or psychotherapy and their children.

All participating mothers needed to be at least 18 years old and have adequate knowledge of the German language. All participating children were born full term. The study protocol was approved by the independent Ethics Committee of the Medical Faculty of Heidelberg University Hospital. Written informed consent was obtained from every participating woman after the study procedures had been fully explained.

\section{Sample Characteristics}

At $\mathrm{T}_{2}$ the age of the women ranged from 26 to 46 years (mean $=38$ years, $\mathrm{SD}=3.11)$ within the overall sample and children's age ranged from 3.17 to 6.00 years (mean $=4.65$ years, $\mathrm{SD}=0.66) ; 33$ of the children $(58.9 \%)$ were male. The distribution of maternal education level in the overall sample was as follows: 2 women (3.6\%) completed low secondary education and 15 (26.8\%) intermediate secondary education; 14 women $(25.0 \%)$ qualified for university entrance, and 25 (44.6\%) held a university degree.

\section{Measures}

Emotional Availability Scales. The EAS [41] consists of six dimensions, four of them addressing the mother's side of EA and two the child's side of EA, all rated on a scale of 1-7. For the purpose of this study, only maternal EA (sensitivity, structuring, nonintrusiveness and nonhostility) was looked at. Maternal sensitivity focuses on genuine affect and responsiveness to the child, and structuring assesses the ability to guide the child and give clues when necessary. Maternal nonintrusiveness refers to the tendency to fol- low the child's lead without being too directive, and maternal nonhostility assesses the absence/presence of negative affect (e.g. boredom, impatience) as well as negative behaviors such as mocking the child. In order to assure reliability, $100 \%$ of the videos were coded by a first trained observer, and $30 \%$ of the videos $(n=19)$ were again rated by a second trained observer. The coders were blinded to the group status of the participants. Cohen's $\kappa$ resulted in $\kappa=0.91$ for maternal sensitivity, $\kappa=0.78$ for maternal structuring, $\kappa=0.82$ for nonintrusiveness, and $\kappa=0.86$ for nonhostility.

Vulnerable Attachment Style Questionnaire. The VASQ is a self-report tool measuring behaviors, feelings, and attitudes regarding adult attachment style based on the Attachment Style Interview [38]. It consists of 22 items rated on a 5-point Likert scale ranging from 'strongly agree' to 'strongly disagree'. Factor analyses divided the VASQ into two main factors: insecurity and proximity seeking. Both scales are related to insecure attachment, whereby the Insecurity Scale is closely related to fearful and angry-dismissive attachment styles, and the Proximity-Seeking Scale is related to an enmeshed attachment style. Cronbach's a was 0.82 for the insecurity scale items and 0.67 for the 10 proximity-seeking items. The test-retest reliability was 0.73 (Pearson's $r, p<0.001$ ) for the insecurity scale and $0.65(\mathrm{p}<0.0001)$ for the Proximity-Seeking Scale.

Structured Clinical Interview for DSM-IV Axis I Disorders. The German SCID-I [34] is a widely used semistructured interview for the measurement and diagnosis of selected Axis I mental syndromes and disorders, according to the criteria of the DSM-IV [42]. The interrater agreement and retest-reliability of the instrument vary from adequate to excellent $[43,44]$.

Theory of Mind. Maternal ToM was assessed using 8 stories taken from the Strange Stories [37] and 2 stories out of the ToM Stories [36]. The mothers were read short vignettes in which a protagonist said things that they did not mean literally, each accompanied by a test question ('Why did X say that?'). A mother's response was categorized into mental explanations (e.g. 'wants to', 'thinks') or physical state explanations (e.g. 'it looks like...'). The answers were rated as (partially) correct or incorrect: 2 points were given if a correct mental state attribution in which mental states were explicitly considered was used, 1 point was given if the explanation was a partially correct mental description (when the explanation was not very elaborated), a score of 0.5 was given if the explanation was a partially correct behavioral description (correct answer on the behavioral level), and 0 points were given in the case of an incorrect explanation or an incorrect/inappropriate mental or behavioral description.

\section{Statistical Analyses}

The Statistical Package for Social Sciences (IBMTM SPSS ${ }^{\circledR}$ v. 23.0) was used for all analyses. To ensure comparability between both groups, differences concerning maternal age, child age, maternal education, and child gender were explored using $t$ tests and $\chi^{2}$ tests before carrying out the main analyses. Group differences in EA between mothers who had been diagnosed with postpartum depression and/or anxiety disorders and healthy mothers were analyzed using t tests. Next, Pearson correlations were conducted to determine which variables were related to maternal EA. As postpartum psychopathology only showed a significant relation to the EA dimension of sensitivity, further calculations were conducted with sensitivity as the outcome measure. In order to figure out whether attachment style insecurity mediated the link between 
postpartum psychopathology and sensitivity, a mediational analysis following Baron and Kenny [45] was calculated. Subsequently, a multiple linear regression analysis was conducted to figure out to which extent the other variables that had shown a significant or marginally significant relation to sensitivity contributed to the prediction of sensitivity.

\section{Results}

\section{Preliminary Analyses}

Analyses regarding comparability between the clinical and the control group revealed no significant differences except for child gender $\left(\chi^{2}=4.93, \mathrm{p}=0.026\right)$. As child gender and the interaction term child gender $\times$ group were not associated with maternal EAS in a one-way MANOVA, we desisted from controlling child gender in further statistical analyses. Descriptive analyses are listed in table 1. Regarding the EA dimensions, mothers scored highest on nonhostility and lowest on sensitivity.

Table 1. Descriptive analyses of the study variables

\begin{tabular}{lcrrr}
\hline & $\mathrm{n}$ & Mean & SD & Range \\
\hline Sensitivity & 56 & 3.76 & 1.16 & $1.5-7.0$ \\
Structuring & 56 & 4.01 & 1.27 & $1.0-6.5$ \\
Nonintrusiveness & 56 & 5.50 & 1.03 & $3.0-7.0$ \\
Nonhostility & 56 & 5.59 & 1.21 & $1.5-7.0$ \\
Attachment style insecurity & 55 & 24.69 & 6.80 & $13-46$ \\
Proximity-seeking style & 55 & 27.13 & 4.00 & $16-35$ \\
ToM & 54 & 12.77 & 3.10 & $5-16$ \\
\hline
\end{tabular}

\section{Main Analyses}

The $t$ tests showed a significant group difference with regard to sensitivity $[\mathrm{t}(54)=3.10, \mathrm{p}=0.003, \mathrm{~d}=0.83]$ but not with regard to the other EA dimensions $(\mathrm{p}>0.05)$. Pearson correlations revealed significant or marginally significant negative associations between all EA dimensions and attachment style insecurity as measured by the VASQ, whereas proximity seeking was not related to maternal EA. Moreover, all EA dimensions were positively correlated with maternal ToM. Maternal postpartum psychopathology was negatively related to sensitivity. Maternal education was positively related to sensitivity and nonintrusiveness (table 2).

Regarding maternal attachment style insecurity, a mediation analysis validated the effect of postpartum psychopathology on attachment style insecurity (model I, $\beta=0.56, t=4.95, p=0.000$ ) and on sensitivity (model II, $\beta=-0.39, t=-3.10, p=0.003)$. Including both predictors in the regression analysis, the effect of postpartum psychopathology on attachment style insecurity did not reach significance $(\beta=-0.14, t=-0.96, p=0.340)$, and therefore maternal attachment style insecurity was validated as a mediator $(\beta=-0.45, \mathrm{t}=-3.12, \mathrm{p}=0.003)$. As the variance inflation factor was 1.46 , multicollinearity seemed unlikely.

In a next step, we conducted a regression analysis with postpartum psychology and attachment style insecurity, as well as the concurrent diagnostic status, ToM, and education, as independent variables to predict sensitivity. It turned out that sensitivity was negatively predicted by attachment style insecurity $(\beta=-0.38, \mathrm{t}=-2.70, \mathrm{p}<0.01)$ and positively predicted by ToM $(\beta=0.29, \mathrm{t}=2.39, \mathrm{p}<$

Table 2. Intercorrelations of the study variables

\begin{tabular}{|c|c|c|c|c|c|c|c|c|c|c|c|}
\hline & & 1 & 2 & 3 & 4 & 5 & 6 & 7 & 8 & 9 & 10 \\
\hline 1 & Sensitivity & 1 & & & & & & & & & \\
\hline 2 & Structuring & $0.82 * * *$ & 1 & & & & & & & & \\
\hline 3 & Nonintrusiveness & $0.38^{* *}$ & 0.16 & 1 & & & & & & & \\
\hline 4 & Nonhostility & $0.53^{* * *}$ & $0.36^{* *}$ & $0.61^{* * *}$ & 1 & & & & & & \\
\hline 5 & Attachment style insecurity & $-0.53^{* * *}$ & $-0.37^{* *}$ & -0.15 & $-0.42^{* *}$ & 1 & & & & & \\
\hline 6 & Proximity-seeking style & -0.10 & -0.12 & 0.13 & 0.10 & $0.34^{*}$ & 1 & & & & \\
\hline 7 & ToM & $0.39^{*}$ & $0.32 *$ & $0.41^{* *}$ & $0.37^{* *}$ & -0.15 & 0.11 & 1 & & & \\
\hline 7 & Education & $0.29^{*}$ & 0.15 & $0.32^{*}$ & $0.25^{\wedge}$ & -0.19 & -0.01 & 0.17 & 1 & & \\
\hline 9 & Postpartum psychopathology & $-0.39 * *$ & -0.21 & -0.07 & -0.12 & $-0.56^{* * *}$ & 0.15 & -0.11 & -0.15 & 1 & \\
\hline 10 & Concurrent psychopathology & $-0.27^{*}$ & -0.14 & -0.16 & -0.19 & $0.47^{* * *}$ & $0.23^{\wedge}$ & -0.05 & $-0.26^{\wedge}$ & $0.65^{* * *}$ & 1 \\
\hline
\end{tabular}

${ }^{*} \mathrm{p} \leq 0.05,{ }^{* *} \mathrm{p} \leq 0.01,{ }^{* * *} \mathrm{p} \leq 0.001, \wedge \mathrm{p} \leq 0.10,2$-tailed Pearson correlations.

Maternal EA, Psychopathology, Attachment and ToM
Psychopathology 2016;49:334-340 DOI: $10.1159 / 000447781$ 
$0.05)$, whereas postpartum $(\beta=-0.15, \mathrm{t}=-0.93, \mathrm{p}=0.357)$ and concurrent psychopathology $(\beta=0.04, \mathrm{t}=0.24, \mathrm{p}=$ $0.815)$ as well as maternal education $(\beta=0.10, t=0.82$, $\mathrm{p}=0.418$ ) did not explain additional variance The overall model explained $36 \%$ of the variance of sensitivity and was highly significant $(\mathrm{F}=5.53, \mathrm{p}<0.001)$.

\section{Discussion}

The aim of the study was to investigate which maternal characteristics were related to maternal EA in the mother-child interaction. Results showed that mothers with postpartum depression and/or anxiety disorders showed less sensitivity toward their child at preschool age than healthy mothers. No significant differences were found with regard to the other EA dimensions. Moreover, it turned out that attachment style insecurity fully mediated the link between postpartum psychopathology and sensitivity, independent from concurrent psychopathology. Besides attachment style insecurity, maternal ToM explained further variance in predicting sensitivity, whereas postpartum and concurrent psychopathology as well as education did not explain unique variance.

In sum, the present study is in line with studies showing that maternal postpartum psychopathology is related to lower maternal sensitivity $[15,16]$. However, we did not find a link between postpartum psychopathology and nonintrusiveness and nonhostility. This could be due to the relatively high socioeconomic status of the study sample, as high intrusiveness seems to be especially prominent in mothers with low socioeconomic status [46]. Moreover, the results of the present study indicate that the negative effect of maternal psychopathology on sensitivity is reduced when maternal attachment style is taken into account: attachment style insecurity fully mediated the link between postpartum psychopathology and sensitivity. These findings are in line with previous studies reporting a link between an insecure attachment representation and low maternal sensitivity [20]. Our findings thus support the notion that an insecure attachment can be more disruptive of parenting quality than depressive or anxious symptoms of the mother [47].

In the present study, proximity seeking as measured by the VASQ was not related to maternal EA. This finding is congruent with Whipple et al. [48], who also did not find a link between preoccupied attachment in the AAI and maternal sensitivity. The present study thus supports previous findings that the proximity-seeking dimension of the VASQ might not be a good indicator of attachment style and requires further validation [24], whereas the attachment insecurity dimension seems to be a valid and good indicator of attachment.

Our result that attachment style insecurity was a stronger predictor of sensitivity than psychopathology is in line with findings showing a buffering effect of maternal attachment security on the mother-child interaction quality [19]. This could be explained by the fact that individuals with an insecure-avoidant attachment style tend to deactivate emotions $[47,49]$, which might lead to lower emotional expressiveness and connectedness with their child. However, it needs to be kept in mind that the present study did not assess attachment representation. Since studies indicate only moderate relations between attachment style and representation [50,51], further research should investigate whether the classically used categorical measure of attachment representation or a dimensional measure of attachment is a better predictor of maternal EA.

Another compelling finding of the present study is that maternal ToM explained unique variance in the prediction of sensitivity. Since this is the first study to relate maternal ToM to the mother-child interaction quality, the results can only be compared with studies showing a link between maternal mind-mindedness and EA [31]. Our findings indicate that mothers who have higher levels of ToM are more emotionally available toward their child.

In sum, the present study showed that mothers with low attachment style insecurity and high ToM skills were more sensitive toward their child, whereas maternal psychopathology did not have a unique effect on sensitivity. These findings support attachment theoretical accounts emphasizing the outstanding role of attachment security as well as good mentalizing skills for healthy child development [3, 52].

Our findings have also important implications for intervention. The finding that maternal attachment style and mentalizing abilities are crucial for the mother-child interaction quality indicate that intervention programs targeting at improving maternal sensitivity should also include sessions in which the mother's attitudes and experiences with close relationships are reflected and in which her ability to correctly interpret other people's mental states is fostered. When the mother is able to recognize the link between her own relational experiences and her relationship with her child, it seems more likely that the vicious circle of intergenerational transmission of attachment can be disrupted.

\section{Limitations and Implications for Future Research}

The present study has some limitations. Firstly, due to the relatively small sample size as well as the high comor- 
bidity of depression and anxiety disorders, it was not possible to systematically investigate differential effects of maternal depression versus anxiety disorders. Secondly, our sample is characterized by an overproportion of academic degrees and, therefore, is not representative of the overall population. Thirdly, due to the cross-sectional design of the study, conclusions about causality, and in particular about the direction of the mediational effect, have to be drawn carefully. Furthermore, other possible covariates that have shown relations to maternal EA, such as child temperament [53], social support [54], and maternal history of trauma [55], were not assessed in the present study. Another factor that might be interesting to investigate is the role of maternal intelligence, as it could be related to maternal ToM and might have a moderating role with regard to the prediction of maternal EA. In sum, future studies should include more covariates in order to get a fuller picture of influence factors on maternal EA. Last but not least, the present study focused on maternal
EA and did not take into account child EA. However, it has to be kept in mind that within the EA framework, maternal and child EA - even though being coded on different dimensions - are strongly interdependent. Thus, in the coding of maternal EA, child EA is, to some extent, always reflected, which should be kept in mind when interpreting the results.

\section{Acknowledgments}

We would like to thank the mothers and children for participating in the study as well as the maternity clinics and their staff in Heidelberg (St. Josef's Hospital, Saint Elisabeth's Hospital, Salem Hospital, and the Gynecological Clinic at the Heidelberg University) and Darmstadt (Alice and Darmstadt Hospital) for their cooperation and support in recruiting patients. The study was supported by a grant from the Program of Research Support of the Medical Faculty of Heidelberg University (funding period: 20032004), the Jacobs Foundation, the Dietmar Hopp Stiftung, and the Köhler and Jung Foundation.

\section{References}

1 Biringen Z, Derscheid D, Vliegen N, Closson L, Easterbrooks A: Emotional availability (EA): theoretical background, empirical research using the EA Scales, and clinical applications. Dev Rev 2014;34:114-167.

2 Ainsworth MDS, Blehar MC, Waters E, Wall S: Patterns of Attachment: A Psychological Study of the Strange Situation. Hillsdale, Lawrence Erlbaum Associates, 1978.

3 Bowlby J: Attachment and Loss: Attachment. London, Hogarth Press, 1969, vol 1.

4 Aviezer O, Sagi A, Joels T, Ziv Y: Emotional availability and attachment representations in Kibbutz infants and their mothers. Dev Psychol 1999;35:811-821.

5 Biringen Z, Damon J, Grigg W, Mone J, PippSiegel S, Skillern S, Stratton J: Emotional availability: differential predictions to infant attachment and kindergarten adjustment based on observation time and context. Infant Ment Health J 2005;26:295-308.

6 Easterbrooks MA, Bureau J-F, Lyons-Ruth K: Developmental correlates and predictors of emotional availability in mother-child interaction: a longitudinal study from infancy to middle childhood. Dev Psychopathol 2012; 24:65-78.

7 Garvin MC, Tarullo AR, van Ryzin M, Gunnar MR: Post-adoption parenting and socioemotional development in post-institutionalized children. Dev Psychopathol 2012;24:3548.

8 Biringen Z, Skillern S, Mone J, Pianta R: Emotional availability is predictive of the emotional aspects of children's 'school readiness'. J Abnorm Child Psych 2005;1:81-97.
9 Howes C, Hong SS: Early emotional availability: predictive of pre-kindergarten relationships among Mexican heritage children? J Abnorm Child Psych 2008;4:4-26.

10 Moreno AJ, Klute MM, Robinson JL: Relational and individual resources as predictors of empathy in early childhood. Soc Dev 2008; 17:613-637.

11 Licata M, Paulus M, Thoermer C, Kristen S, Woodward A, Sodian B: Mother-infant interaction quality and infants' ability to encode actions as goal-directed. Soc Dev 2014;23: 340-356.

12 Reck C, Hunt A, Fuchs T, Weiss R, Noon A, Möhler E, Downing G, Tronick E, Mundt C: Interactive regulation of affect in postpartum depressed mothers and their infants: an overview. Psychopathology 2004;37:272-280.

13 Reck C, Noe D, Stefenelli U, Fuchs T, Cenciotti F, Stehle E, Mundt C, Downing G, Tronick E: Interactive coordination of currently depressed inpatient mothers and their infants during the postpartum period. Infant Ment Health J 2011;32:542-562.

14 Beck CT: The effects of postpartum depression on maternal-infant interaction: a metaanalysis. Nurs Res 1995;44:298-304.

15 Murray L, Cooper P, Hipwell A: Mental health of parents caring for infants. Arch Womens Ment Health 2003;6:71-77.

16 Easterbrooks MA, Biesecker G, Lyons-Ruth $\mathrm{K}$ : Infancy predictors of emotional availability in middle childhood: the roles of attachment security and maternal depressive symptomatology. Attach Hum Dev 2000;2:170-187.
17 Reck C, Nonnenmacher N, Zietlow AN: Intergenerational transmission of internalizing behavior: the role of maternal psychopathology, child responsiveness and maternal attachment style insecurity. Psychopathology 2016, accepted.

18 Reck C, Struben K, Backenstrass M, Stefenelli U, Reinig K, Fuchs T, Mundt SC: Prevalence, onset and comorbidity of postpartum anxiety and depressive disorders. Acta Psychiatr Scand 2008;118:459-468.

19 Van Ee E, Kleber RJ, Mooren TTM: War trauma lingers on: associations between maternal posttraumatic stress disorder, parent-child interaction, and child development. Infant Ment Health J 2012;33:459-468.

20 Ward MJ, Carlson EA: Associations among adult attachment representations, maternal sensitivity, and infant-mother attachment in a sample of adolescent mothers. Child Dev 1995;66:69-79.

21 McMahon C, Barnett B, Kowalenko NM, Tennant CC: Maternal attachment state of mind moderates the impact of postnatal depression on infant attachment. J Child Psychol Psychiatry 2006;47:660-669.

22 George C, Kaplan M, Main N: The Adult Attachment Interview. Unpublished Manual. Berkeley, University of California at Berkeley, 1985.

23 Biringen Z, Matheny A, Bretherton I, Renouf A, Sherman M: Maternal representation of the self as parent: connections with maternal sensitivity and maternal structuring. Attach Hum Dev 2000;2:218-232. 
24 Oyen AS, Landy S, Hilburn-Cobb C: Maternal attachment and sensitivity in an at-risk sample. Attach Hum Dev 2000;2:203-217.

25 Griffin D, Bartholomew K: Models of the self and other: fundamental dimensions underlying measures of adult attachment. J Pers Soc Psychol 1994;67:430-445.

26 Bifulco A, Mahon J, Kwon JH, Moran PM, Jacobs C: The Vulnerable Attachment Style Questionnaire (VASQ): an interview-based measure of attachment styles that predicts depressive disorder. Psychol Med 2003;33: 1099-1110.

-27 Fraley RC, Shaver PR: Adult romantic attachment: theoretical developments, emerging controversies, and unanswered questions. Rev Gen Psychol 2000;4:132-154.

-28 Edelstein RS, Alexander K, Shaver PR, Schaaf JM, Quas JA, Lovas GS, Goodman GS: Adult attachment style and parental responsiveness during a stressful event. Attach Hum Dev 2004;6:31-52.

29 Carpendale JIM, Lewis C: Constructing an understanding of mind: the development of children's social understanding within social interaction. Behav Brain Sci 2004;27:79-96.

30 Baron-Cohen S, Tager-Flusberg H, Cohen DJ: Understanding Other Minds: Perspectives from Autism. Oxford, Oxford University Press, 1993.

31 Meins E: Security of Attachment and the Social Development of Cognition: Security of Attachment and the Social Development of Cognition. Hove, Psychology Press, 1997.

32 Lok SM, McMahon CA: Mothers' thoughts about their children: links between mindmindedness and emotional availability. $\mathrm{Br}$ Dev Psychol 2006;24:477-488.

- 33 Zietlow A, Schlüter MK, Nonnenmacher N, Müller M, Reck C: Maternal self-confidence postpartum and at pre-school age: the role of depression, anxiety disorders, maternal attachment insecurity. Matern Child Health 2014;18:1873-1880.

34 Meiser S, Zietlow AL, Reck C, Träuble B: The impact of postpartum depression and anxiety disorders on children's facial emotional expression processing at pre-school age. Arch Womens Ment Health 2015;18;707-716.
35 Reck C, Zietlow AL, Muller M, Dubber S: Perceived parenting stress in the course of postpartum depression: the buffering effect of maternal bonding. Arch Womens Ment Health 2016;19:473-482.

36 Reck C, Struben K, Backenstrass M, et al: Prevalence, onset and comorbidity of postpartum anxiety and depressive disorders. Acta Psychiatr Scand 2008;118:459-468.

37 Wittchen HU, Wunderlich U, Gruschwitz S, Zaudig M: Strukturiertes klinisches Interview für DSM- IV, Achse I (SKID). Göttingen, Hogrefe, 1997.

38 Bifulco A, Moran P, Ball C, Bernazzani O: Adult attachment style. I. Its relationship to clinical depression. Soc Psychiatry Psychiatr Epidemiol 2002;37:50-59.

39 Fletcher PC, Happé F, Frith U, Baker SC, Dolan RJ, Frackowiak RSJ, Frith CD: Other minds in the brain: a functional imaging study of 'theory of mind' in story comprehension. Cognition 1995;57:109-128.

40 Happé F: An advanced test of theory of mind: understanding of story characters' thoughts and feelings by able autistic, mentally handicapped, and normal children and adults. J Autism Dev Disord 1994;24:129-154.

41 Biringen Z: The Emotional Availability (EA) Scales, ed 4. Unpublished Manual. Boulder, Colorado State University, 2008.

42 American Psychiatric Association: Diagnostic and Statistical Manual of Mental Disorders, ed 4, text rev. Washington, American Psychiatric Association, 2000

43 Sass H, Wittchen HU, Zaudig M: Diagnostisches und Statistisches Manual Psychischer Störungen - DSM-IV. Göttingen, Hogrefe, 1994.

44 Zanarini MC, Skodol AE, Bender D, Dolan R, Sanislow C, Schaefer E, Morey LC, Grilo CM, Shea MT, McGlashan TH, Gunderson JG: The collaborative longitudinal personality disorders study: reliability of axis I and II diagnoses. J Pers Disord 2000;14:291-299.

45 Baron RM, Kenny DA: The moderator-mediator variable distinction in social psychological research: conceptual, strategic, and statistical considerations. J Pers Sol Psychol 1986; 51:1173-1182.
6 Tamis-LeMonda CS, Briggs RD, McClowry SD, Snow DL: Maternal control and sensitivity, child gender, and maternal education in relation to children's behavioral outcomes in African American families. J Appl Dev Psychol 2009;30:321-331.

47 Kim BR, Teti DM, Cole PM: Mothers' affect dysregulation, depressive symptoms, and emotional availability during mother-infant interaction. Infant Ment Health J 2012;33: 469-476.

48 Whipple N, Bernier A, Mageau GA: Broadening the study of infant security of attachment: maternal autonomy - support in the context of infant exploration. Soc Dev 2011;20:17-32.

49 Fraley RC, Shaver PR: Adult attachment and the suppression of unwanted thoughts. J Pers Soc Psychol 1997,73:1080-1091.

50 Bartholomew K, Shaver P: Methods of assessing adult attachment: do they con-verge?; in Simpson JA, Rholes WS (eds): Attachment Theory and Close Relationships. New York, Guilford, 1998, pp 25-45.

51 Shaver PR, Belsky J, Brennan KA: Comparing measures of adult attachment: an examination of interview and self-report methods. Pers Relatsh 2000;7:25-43.

52 Baron-Cohen S: Theories of the autistic mind. Psychologist 2008;21:112-116.

53 Casalin S, Tang E, Vliegen N, Luyten P: Parental personality, stress generation, and infant temperament in emergent parent-child relationships: evidence for a moderated mediation model. J Soc Clin Psychol 2014;33: 270-291.

54 Stack DM, Serbin LA, Girouard N; Enns LN, Bentley VMN, Ledingham JE, Schwartzman AE: The quality of the mother-child relationship in high-risk dyads: application of the Emotional Availability Scales in an intergenerational, longitudinal study. Dev Psychopathol 2012;24:93-105.

55 Moehler E, Biringen Z, Poustka L: Emotional availability in a sample of mothers with a history of abuse. Am J Psychiatry 2007;77:624628. 